\title{
Attitudes of Vegetable Farmers Towards Public Agricultural Extension Services
}

\author{
${ }^{1}$ Tala Qtaishat and ${ }^{2}$ Ali AL-Sharafat \\ ${ }^{1}$ Department of Agricultural Economics and Agribusiness, \\ Faculty of Agriculture, University of Jordan, Amman, 11942, Jordan \\ ${ }^{2}$ Department of Agricultural Economics and Extension, \\ Faculty of Agriculture, Jerash University, Jerash, 26150, Jordan
}

Received 2012-02-29, Revised 2012-05-13; Accepted 2012-05-19

\begin{abstract}
Among vegetable farmers in Jordan, there are conflicting attitudes towards the extension activities provided by the public sector. Some farmers accept and adopt the recommendations of these activities; on the other hand, some people are not satisfied and consider these activities a waste of time for both the farmers and the government. This situation has serious impacts on the quality, duration and efficiency of the extension activities provided by government related agencies. Also, the situation will end in providing low-quality agricultural extension services to the farmers or providing these services in a non-productive manner. The actual attitudes of vegetable farmers towards Public Agricultural Extension Services (PAES) in the Dear Alla Area of Jordan were investigated in this study. A total of 80 vegetable farmers were selected for the study. A questionnaire consisting of two main parts was used for data collection; the first part was related to personal and socio-economic characteristics of the sample individuals. The second part was related to extension activities. A five-point Likerttype scale was used as an instrument to gather primary data. The farmers rated their attitudes toward Public Agricultural Extension Services (PAES) through 10 statements related carefully to the Public Agricultural Extension Services. Data analysis was done in two sections, consisting of data description and data inferential analysis. The results of the study revealed that the farmers' overall attitude towards the public agricultural extension activities was negative. The farmers' attitudes according to age, experience, educational level and frequency and type of contact with public extension services were also negative. The negative attitude of the participant farmers towards the Public Agricultural Extension Services means that the farmers were not satisfied with these services. Identifying the sources and types of public extension programs, the provision of legal and policy framework, farmer' participation, the determination of public extension functions, providing skilled manpower and networking and enhancing the capabilities of public extension service providers may aid in changing the farmers' attitudes towards the Public agricultural extension services to be positive.
\end{abstract}

Keywords: Vegetable Farmers, Public Extension, Attitudes

\section{INTRODUCTION}

Many countries established their agricultural extension systems in order to realize their national food security goals (Swanson, 2009; Umali-Deininger and Schwartz, 1994; Hu et al., 2009). The term "agricultural extension" is a professional communication intervention deployed by organizations to disseminate agriculture knowledge and technologies to rural communities. Extension has a long history, based on adult education, communication science, community development, rural development and international development and has strong linkages with agriculture research and practice (Karbasioun et al., 2007).
Attitudes are considered the main constraints to the adoption rates of vegetable technology by farmers and consequently, vegetable production is affected by these attitudes. The effectiveness of extension services is highly dependent on the ability of extension workers who are competent because the entire extension process is dependent on them to transfer information from extension organizations to the clients. The movement of technology from the lab to the field has been a challenge for agricultural extension agents. Performance of extension agents is expected to increase if they have program-development competencies to keep extension agents competent and to further improve their performance, these competencies must be considered and upgraded and continuous 
assessment of extension agents' competencies and performance is recommended The extension agents' assessment process has a direct relationship to the farmers' attitudes towards the agricultural extension services provided by those agents (Hindi, 2009).

However, serious reservations are being expressed about the performance and capability of this sector, placing the future of the public extension system in doubt. Rivera (1987), for example, argues that the performance of public agricultural extension in developing countries has been disappointing and has failed to transfer agricultural technology to the farmers.

In order to deploy an appropriate technology for extension service, financial, social, human and organizational sustainability should be achieved over time and policies that provide affordable access to information need to be carefully identified and examined (Hosseini et al., 2009). The process of deploying appropriate technology for extension service requires measuring the attitudes of the farmers towards the provided agricultural extension services; otherwise this process is not viable.

Identifying extension's organizational characteristics for supporting agriculture is one of the major approaches that needs to be carefully thought about and accurately implemented during the extension system's development. Agriculture agencies have to take the responsibility for intensifying aspects of job satisfaction, organizational policy and management style, work environment and remuneration (Azril et al., 2010). A more open employeefriendly organizational policy has proven to enhance employee work performance as stressed by Tella et al. (2007) and Mastura et al. (2006). Success of any agricultural extension program depends largely on the optimum selection of extension activities; methods, goals and the farmers' preference of extension methods (Seevers, 1997). In Jordan, like other developing countries, agricultural extension activities are considered to be one of the most important activities in achieving comprehensive rural development by transferring technologies from research stations to the farmers. The increased farmer participation in sustainable agricultural development programs and agricultural extension services, decentralizing from activities and facilitating to apply local groups is the most important approach for agricultural extension in the future (Allahyari, 2009). The main objective of this study is to measure the attitudes of vegetable farmers towards public agricultural extension activities in the Dear Alla area of Jordan.

\subsection{The Agricultural Extension System}

The Agricultural Extension System (AES) can be defined as an agricultural information exchange system which shows the actors, people and institutions; their interactions and communication networks among these actors to coordinate the information related processes
(Demiryurek, 1999). Many practices may be included in the AES. For example, the AES management organizes to place posters along the main roads where farmers can easily see them and broadcasts agricultural information through the television and radio in the agriculture section. Agricultural newsletters and pamphlets are distributed to farmers during the seasonal crop production periods (Cho and Boland, 2004).

Extension comprises several of the following functions (IBRDWB, 1994):

- Diagnosis of farmers' socio-economic and agro-ecological conditions as well as well as their opportunities and constraints

- Message transfer through direct contact between the extension agent and farmer; or through indirect contact involving intermediaries such as "contact farmers" or voluntary organizations through training courses and through mass media. Messages may be comprised of advice, awareness creation, skill development and education

- Feedback to researchers on the farmers' reactions to new technology the refines the future research agenda

- Development of linkages with researchers, government planners, Non Governmental Organizations (NGOs), farmers' organizations, banks and the private commercial sector. In remote areas, extension agents have taken on a number of these functions directly

- Monitoring the extension system and evaluation of its performance at the farm level

\subsection{Providers of Public Agricultural Extension Services in Jordan}

The United States Agency for International Development (USAID) published in 2005 an assessment report about agricultural extension in Jordan. According to the report three Jordanian government organizations are responsible for the delivery of public agricultural extension inputs and advice to Jordanian farmers. They are the Ministry of Agriculture (MoA) and its affiliated National Center for Research and Technology Transfer (NCARTT), recently known as The National Center for Agricultural Research and Extension (NCARE) and the Jordan Valley Authority (JVA).

\subsection{MoA}

The main public organization responsible for providing agricultural extension services is the MoA. The MoA employs 117 staff members to provide extension services throughout Jordan. The organization and qualifications of the extension staff are shown in Table 1 and 2. 
Table 1. MoA staff in the extension service

\begin{tabular}{lcccc}
\hline & Numbers & & \\
\cline { 2 - 5 } & Female & Male & Total & $\begin{array}{c}\text { Proportion } \\
(\%)\end{array}$ \\
\hline $\begin{array}{l}\text { Extension agent } \\
\text { Head of }\end{array}$ & 23 & 59 & 82 & 71 \\
$\begin{array}{l}\text { Extension center } \\
\text { Head of }\end{array}$ & - & 4 & 4 & 3 \\
department & 3 & 16 & 19 & 16 \\
$\begin{array}{l}\text { Observer } \\
\text { Total }\end{array}$ & 2 & 10 & 12 & 10 \\
\hline
\end{tabular}

Source: USAID (2005).

Table 2. Qualifications held by MoA extension service staff

\begin{tabular}{lcc}
\hline Scientific degree & Number & Proportion (\%) \\
\hline PhD & 2 & 71 \\
MSc & 3 & 3 \\
Diploma & 12 & 16 \\
BSc & 100 & 10 \\
Total & 117 & 100 \\
\hline
\end{tabular}

Source: USAID (2005).

\subsection{NCARE}

NCARE has produced about 100 advisory tri-fold leaflets and some booklets in Arabic on crops, fruit, vegetables, pest and disease control, livestock and fertilizer applications. However, most of these materials are outdated and too general to be of specific use by farmers (USAID, 2005).

\subsection{JVA}

The JVA is responsible for delivering water to farms in the Jordan Valley. The JVA has produced information about irrigation systems, water use and irrigation scheduling. The JVA currently does not provide extension services for on-farm water management. The JVA has produced information about irrigation systems, water use and irrigation scheduling. Under the Irrigation Advisory Service (IAS) project, extension services produced information on using tensiometers to monitor evapotranspiration water loss and crop water requirements to schedule irrigation. The JVA has produced information with German Agency for Technical Cooperation (GTZ) support on the use of brackish water for crop production. All this information looked well-produced and appropriately targeted to the farmer clientele (USAID, 2005).

\section{MATERIALS AND METHODS}

\subsection{The Sample}

The population of this study included all the vegetable farmers in one of the most important vegetable production areas in the Jordan Valley, the Dear Alla area. The total number of those farmers is 1675 (MoA, 2009). The sample was obtained through a simple random-sampling technique. The sample size was determined according to the following equation:

$$
\mathrm{n}=\mathrm{p} \times \mathrm{q}(\mathrm{Zx} / \mathrm{e})^{2}
$$

Where:

$$
\begin{aligned}
\mathrm{n}= & \text { Sample size } \\
\mathrm{p}= & \text { Success in the proportion of the population } \\
(1-\mathrm{P})= & \text { Failure in the proportion of the population } \\
\mathrm{Z} / 2= & 1.645 \text { ( } \mathrm{Z} \text {-value used in a } 90 \% \text { confidence } \\
& \text { interval) } \\
\mathrm{e}= & \text { Degree of error }(10 \%)
\end{aligned}
$$

Therefore, with $\mathrm{p}=0.50$ and $(1-\mathrm{p})=0.50, \mathrm{n}$ will be:

$$
\mathrm{n}=0.50 \times 0.50(1.645 / 0.10)^{2}=68
$$

The sample size was determined at a confidence level of 0.90; this level was an appropriate level due to the reason that the population itself was relatively small in size. The term error was 0.10 and the $\mathrm{Z}$ value corresponding to this level was 1.645. The success in the proportion of the population or the proportion that the sample will occur $(p)$ was equal to 0.50 and the failure in the proportion of the population or the proportion that the sample will not occur (1-p) was also equal to 0.5 . The sample size according to the above-mentioned equation was 68. An additional 12 farmers were interviewed for precision purposes.

\subsection{Data Collection}

The primary data were collected during the vegetable season of 2008-2009 through a structured questionnaire which was designed to obtain information from farmers. Questionnaire reliability was estimated by calculating Cronbach's alpha and it was appropriate for this study (0.86). The questionnaire consisted of two main parts; the first part was related to personal and socio-economic characteristics of the sample individuals. The second part was related to extension activities. The secondary data were achieved from their normal related sources; MoA, NCARE, JVA, Department of Statistics (DoS) and their related published studies. A five-oint Likert-type scale was used as the instrument to gather primary data in order to measure the attitudes of vegetable farmers towards public agricultural extension activities in the study area. The Likert scale was named after its inventor, the U.S. organizationalbehavior psychologist Dr. Rensis Likert who published a report describing its use. A Likert-type scale is an attitudemeasuring instrument that is frequently used in persuasion studies. It is a psychometric scale commonly used in questionnaires and is considered the most widely used method of ascribing quantitative value to qualitative data, to make the data amenable to statistical analysis. Likert scales usually have five potential choices, such as (not important, slightly important, neutral, important, very important), or (strongly favorable, favorable, neutral, not favorable, strongly not favorable) but, sometimes, go up to ten or 
more. A numerical value is assigned to each potential choice and mean figure for all the responses is computed at the end of the evaluation or survey. The final average score represents the overall level of accomplishment or attitude toward the subject matter. When responding to a Likert questionnaire item, respondents specify their level of agreement to a statement (Vagias, 2006).

In this study, the ratings on the Likert scale were from one to five, with one being "strongly disagree', two being "disagree", three being "neutral", four being "agree" and five being "strongly agree". The final mean score represented the overall level of attitude toward the item assigned for each statement regarding the public extension activities. Mean scores of 2.50 and above were regarded with positive attitude toward the public extension services while scores less than 2.50 illustrated negative attitude toward these services. Farmers rated their attitudes toward Public Agricultural Extension Services (PAES) through the statements shown in Table 3.

\subsection{Data Analysis}

A quantitative analysis using data gathered by the survey questionnaire and Likert scale was used. Data were analyzed using the Statistical Package for the Social Sciences (SPSS). To reach the research objectives, appropriate statistical procedures for description were used. Data analysis was carried out through data description and data inferential analysis. Statistics, such as frequencies, percentages, cumulative percentages, standard deviations, means and medians, were used in the descriptive section. An inferential analysis, assigning a numerical value to each potential choice was used and a mean figure for all the responses was computed. Correlations were run between selected extension variables.

Table 3. Statements used in measuring farmers' attitudes

\begin{tabular}{|c|c|}
\hline $\begin{array}{l}\text { Number of } \\
\text { statement }\end{array}$ & Statement \\
\hline 1. & PAES are easy to be achieved when needed \\
\hline 2. & $\begin{array}{l}\text { PAES are dependable, practical and can be trusted } \\
\text { to be as accurate as possible }\end{array}$ \\
\hline 3. & $\begin{array}{l}\text { PAES offered through various methods } \\
\text { (exhibitions, workshops, discussions, day } \\
\text { fields, leaflets, office visits) }\end{array}$ \\
\hline 4. & PAES seem to be the same from year to year. \\
\hline 5. & $\begin{array}{l}\text { PAES provide possible solutions to } \\
\text { the farmers' problems }\end{array}$ \\
\hline 6. & $\begin{array}{l}\text { PAES assist the farmer in planning and decision } \\
\text { making aspects in his agricultural activity }\end{array}$ \\
\hline 7. & Only resourceful farmers can get the benefit of PAES \\
\hline 8. & PAES improve farmer's income \\
\hline 9. & $\begin{array}{l}\text { Existing infrastructure and facilities of PAES are } \\
\text { enough to meet the needs of the farmers }\end{array}$ \\
\hline 10 . & $\begin{array}{l}\text { PAES are less efficient compared to agricultural } \\
\text { extension services provided by private sector }\end{array}$ \\
\hline
\end{tabular}

\section{RESULTS}

The demographic profile and the descriptive statistics were investigated in the first place. Table 4 shows the demographic profile and the descriptive statistics for some characteristics of the participant farmers.

The results of the demographic information and the descriptive statistics of the participant farmers indicated that all participants were men who were 46.8 years old on average. The minimum age of participant farmers was 22 years and the maximum age was 71 years. Regarding participants' education levels, a greater proportion of them $(57.5 \%)$ had had a basic level of education. Only $2.5 \%$ of participants had graduate education.

Fifty-two percent of the participants had fewer than 21 years of work experience. Their average work experience was 19 years. Table 5 shows the mean score by statement in rank order as well as the overall level of attitude toward Public Agricultural Extension Services. The mean score of the items in the scale represents the farmers' attitude towards Public Agricultural Extension Services.

The age of clients, their experience, their educational level and their frequency and type of contact with public extension services are characteristics of interest and concern to extension professionals. To examine if there is any difference in the way different groups of farmers, according to these characteristics, felt about public extension services, the mean value was calculated by farmers' age, experience, education level, frequency of contact and the type of contact they had with public extension services (Table 6-10).

Table 6 shows that all age groups of farmers had a negative attitude towards public extension services (less than 2.5). The average attitude value according to the age of farmers was 1.64. All age groups had almost the same attitude value except the 62-71 group. The attitude value for this group was 1.50 followed by the 52-61 group with an attitude value of 1.62 .

Table 7 shows that, according to their experience in farming, all farmer groups had a negative attitude towards public extension services (less than 2.5). The average attitude value according to farmers' educational level was 1.69. The participating farmers averaged 26.5 years of experience in farming. All groups, except the 42-51 group had almost the same attitude value. The attitude value for this group was 1.90. The results shown in Table 7 indicated that approximately two-thirds $(52$ farmers $=65 \%$ ) of the participating farmers had 12-31 years of experience. Ten farmers $(12.5 \%)$ had $32-51$ years of experience. Eighteen farmers $(22.5 \%)$ had 2-11 years of experience.

The agricultural extension function is educational and consequently, the formal education level is an important consideration. The results presented in Table 8 show that, as the educational level of the participant farmers increases, the attitude score is higher. Nevertheless, all groups of farmers, according to their educational level, had a negative attitude towards public extension services (less than 2.5). The average attitude value according to farmers' educational level was 1.75. 
Table 4. Demographic profile and descriptive statistics of some characteristics of the participant farmers

\begin{tabular}{|c|c|c|c|}
\hline Variable name & Frequency & Percentage & Mean \\
\hline \multicolumn{4}{|l|}{ Gender } \\
\hline Males & 80 & 100.000 & \multirow{10}{*}{46.78} \\
\hline Females & 00 & 000.000 & \\
\hline Total & 80 & 100.000 & \\
\hline Age (years) & & & \\
\hline $22-31$ & 7 & 8.750 & \\
\hline $32-41$ & 21 & 26.250 & \\
\hline $42-51$ & 26 & 32.500 & \\
\hline $52-61$ & 17 & 21.250 & \\
\hline $62-71$ & 9 & 11.250 & \\
\hline Total & 80 & 100.000 & \\
\hline Experience (years) & & & \multirow{15}{*}{19.13} \\
\hline $2-11$ & 18 & 22.500 & \\
\hline $12-21$ & 34 & 42.500 & \\
\hline $22-31$ & 18 & 22.500 & \\
\hline $32-41$ & 08 & 0010.000 & \\
\hline $42-51$ & 02 & 2.500 & \\
\hline Total & 80 & 100.000 & \\
\hline \multicolumn{3}{|l|}{ Education Level } & \\
\hline 1. Illiterate & 03 & 3.750 & \\
\hline 2. Basic & 46 & 57.500 & \\
\hline 3. High school & 19 & 23.750 & \\
\hline 4. Community college & 10 & 12.500 & \\
\hline 5. Graduate & 02 & 2.500 & \\
\hline 6. Post graduate & 00 & 0000.000 & \\
\hline Total & 80 & 100.000 & \\
\hline
\end{tabular}

Source: Prepared by the researchers based on the study survey.

Table 5. Mean rankings concerning Public Agricultural Extension Services (PAES)

\begin{tabular}{llccc}
\hline $\begin{array}{l}\text { Number of } \\
\text { statement }\end{array}$ & $\begin{array}{l}\text { Number of } \\
\text { respondents }\end{array}$ & Mean & $\begin{array}{l}\text { Standard } \\
\text { deviation }\end{array}$ & Rank \\
\hline 1 & 80 & 1.21 & 0.441 & 8 \\
2 & 80 & 1.16 & 0.371 & 9 \\
3 & 80 & 1.22 & 0.412 & 7 \\
4 & 80 & 2.64 & 0.860 & 2 \\
5 & 80 & 1.31 & 0.542 & 4 \\
6 & 80 & 1.15 & 0.359 & 10 \\
7 & 80 & 2.46 & 0.941 & 3 \\
8 & 80 & 1.28 & 0.528 & 6 \\
9 & 80 & 1.30 & 0.604 & 5 \\
10 & 80 & 2.68 & 0.911 & 1 \\
Average & & 1.64 & & \\
\hline Source: Prepar &
\end{tabular}

Source: Prepared by the researchers based on the study survey.

Table 6. Attitudes by age group

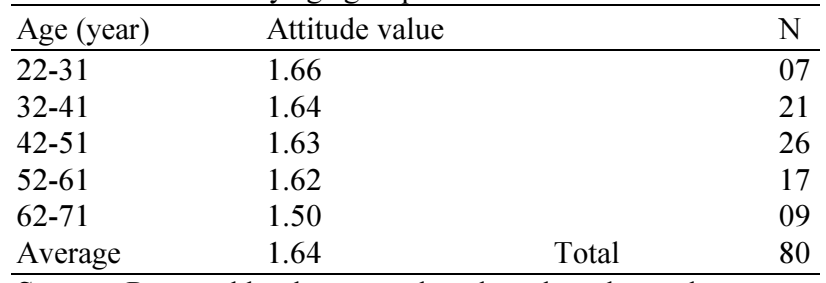

Source: Prepared by the researchers based on the study survey.
Table 7. Attitudes by farmers' experience

\begin{tabular}{llll}
\hline Experience (year) & Attitude value & $\mathrm{N}$ \\
\hline $02-11$ & 1.61 & & 18 \\
$12-21$ & 1.66 & & 34 \\
$22-31$ & 1.68 & & 18 \\
$32-41$ & 1.60 & & 08 \\
$42-51$ & 1.90 & Total & 02 \\
Average & 1.69 & 80 \\
\hline
\end{tabular}

Source: Prepared by the researchers based on the study survey.

Table 8. Attitudes by farmers' education level;

\begin{tabular}{|c|c|c|c|}
\hline$\overline{\text { Education level }}$ & Attitude value & & $\mathrm{N}$ \\
\hline Illiterate & 1.47 & & 03 \\
\hline Basic & 1.59 & & 46 \\
\hline High school & 1.63 & & 19 \\
\hline Community college & 1.84 & & 10 \\
\hline Graduate & 2.20 & & 02 \\
\hline Average & 1.75 & Total & 80 \\
\hline
\end{tabular}

Source: Prepared by the researchers based on the study survey.

Table 9. Attitudes by frequency of contact;

\begin{tabular}{lll}
\hline Frequency of contact & Attitude value & $\mathrm{N}$ \\
\hline None & 1.48 & 10 \\
Seldom & 1.48 & 09 \\
Occasional & 1.62 & 30 \\
Frequent & 1.70 & 22 \\
Regular & 1.77 & 09 \\
Average & 1.61 & Total \\
Source: Prepared by the researchers based on the study survey
\end{tabular}

Source: Prepared by the researchers based on the study survey.

Table 10. Attitudes by type of contact;

\begin{tabular}{|c|c|c|}
\hline Frequency of contact & Attitude value & $\mathrm{N}$ \\
\hline Agricultural exhibitions & 1.85 & 06 \\
\hline Workshops & 1.54 & 07 \\
\hline Seminars, lectures, discussions & 1.60 & 06 \\
\hline Mass media & 1.53 & 09 \\
\hline Leaflets & 1.60 & 02 \\
\hline Field visits & 1.63 & 27 \\
\hline Office visits & 1.67 & 23 \\
\hline Average & Total & 80 \\
\hline
\end{tabular}

Source: Prepared by the researchers based on the study survey.

Farmers' attitudes according to the frequency and type of contact with Public Agricultural Extension Services were examined to see if any relationship existed between attitude scores and the type/frequency of contact with extension. Table 9 shows the attitude values of the participating farmers according to frequency of contact with Public Agricultural Extension Services.

The relationship between farmers' attitudes those farmers had with extension services was examined. Table 10 shows the attitude values of the participating those farmers had with extension services. Farmers rated exhibitions, field visits and office visits with the highest attitude values $(1.85,1.63$ and 1.67), respectively.

\section{DISCUSSION}

The results of the demographic information (Table 4) implies that more attention should be paid to 
the basic level category. Extension programs should consider this category when implementing public agricultural extension programs. Inequality in the farmers' scientific knowledge needs to be taken into consideration when preparing public agricultural extension programs and extension methodologies.

The results presented in Table 5 revealed that the farmers' overall mean value was 1.64 , indicating a negative attitude toward the public agricultural extension activities (The mean value is less than 2.5). This finding meant that the farmers were not satisfied with those services. The results also revealed that farmers considered the Public Agricultural Extension Services less efficient compared to the agricultural extension services provided by the private sector (highest mean value; 2.68). This statement was ranked as the first in its importance to the farmers. This ranking may be attributed to fact that the public extension employees are not interested in benefiting the farmer. A rank of one meant that the farmers were interested, first of all, in the source of agricultural extension services. The second highest mean value (2.64) was recorded for statement number 4, indicating that the Public Agricultural Extension Services seems to be the same every year, which means that the procedures and methods followed in providing services were not subjected to any noticed improvement. From the mean value of statement number 7 (mean value $=2.46$ ), it could be concluded that, from farmers' viewpoints, only resourceful farmers can get the benefit of Public Agricultural Extension Services. The farmers felt that it was not easy to reach the Public Agricultural Extension Services when needed (mean value $=1.21$ ) and they also felt that the Public Agricultural Extension Services were not dependable or practical and cannot be trusted to be as accurate as possible (mean value $=1.16$ ). Regarding the methods of extension, the farmers believed that these services were provided through limited and traditional methods (mean value $=1.22$ ). Due to the low satisfaction by farmers with the Public Agricultural Extension Services farmers believed that those services did not provided any possible solutions for their agricultural problems (mean value $=1.31$ ). PAES did not assist the farmer with planning and decision-making aspects for his agricultural activity (mean value $=1.15$ ), hence PAES did not improve a farmer's income (mean value $=1.28$ ). These problems facing the Public Agricultural Extension Services may be attributed to the fact that the existing infrastructure and facilities of those services are not enough to meet the needs of the farmers (mean value $=1.3$ ).

The results shown in Table 6 indicated that the majority (71 farmers $=89 \%$ ) of the participating farmers were in the middle age (22-31, 32-41, 42-51 and 52-61) groups and, hence, belonged to an active and productive age. Only a few ( 9 farmers $=11 \%$ ) were over 62 years. The mean age was 46.5 years, indicating that most of the respondents were young and able-bodied men. The public extension services were introduced to all these age groups equally and the farmers were not satisfied with these services. Farmers in most age groups expressed disagreement with the procedures and methods used in providing the extension services and this sentiment may partially explain the lower attitude scores. These findings are indicators for the public extension providers to make a special effort to consider this disagreement when providing public extension services and building extension programs. The farmers' attitude could be attributed to poor quality and ineffective extension services. Unclear working methods as well as limited competence and motivation for public sector extension agents are other reasons.

The results presented in Table 7 indicated that the participating farmers had a lot of experience in farming, which is necessary to apply extension advice. Even so, the farmers were not satisfied with the provided public extension services, meaning that there was a gap between public extension service providers and public extension service receivers. This gap should be bridge.

The results presented in Table 8 showed that the illiterate farmers (4\%) had the lowest attitude value (1.47) and the graduate-educated farmers (3\%) had the highest attitude value (2.20). Farmers with basic and high school educational levels were the majority $(81 \%)$ and had attitudes values of 1.59 and 1.63 , respectively. This low level of education is likely to have a negative effect on farmers' understanding about the technical aspects of the advisory officers' work. It prevents them from applying proper methodologies and appropriately recommended agricultural techniques, hence, they adopt negative attitude towards extension services.

The rating presented in Table $\mathbf{1 0}$ means that the farmers were participating effectively in those rated activities compared to the other extension activities. The activities received the lowest attitude values were workshops and mass media with attitude values of 1.54 and 1.53, respectively. These findings means that farmers' participation in those activities was a minimal in leaflet activity, with mean attitude values of 1.60 for both. The farmers' level of participation in these types of services is the main reason for their negative attitude towards the public extension services. This situation could be attributed to insufficient awareness of those farmers about extension types.

\section{CONCLUSION}

The results of this study revealed that the farmers' attitude towards the Public Agricultural Extension Activities was negative. This attitude means that the farmers were not satisfied with these services. The 
results also revealed that farmers considered the Public Agricultural Extension Services less efficient compared to the agricultural extension services provided by the private sector. The Public Agricultural Extension Services seemed to be the same every year, meaning that the procedures and methods followed in providing those services were not subjected to any noticed improvement. The farmers felt that it was not easy to benefit from the Public Agricultural Extension Services when needed and they also felt that the Public Agricultural Extension Services were not dependable or practical and that PAES cannot be trusted to be as accurate as possible. The farmers believed that these services were provided through limited and traditional methods, resulting in no assistance to the farmers with planning and decision-making aspects.

Attitudes of participating farmers according to age, experience, education level and frequency and type of contact with public extension services were negative, confirming the result obtained about the overall attitude of farmers towards public extension services.

In light of the findings from the study, the following recommendations, among others, were made:

- Sources and types of public extension programs should be identified and the capabilities of extension service providers should be enhanced

- Policy framework for public extension should be provided

- Legal framework for public extension should be provided

- Extension activities should be planned with the full involvement of farmers to increase their level of participation

- Functions that constitute public extension should be determined

- Qualified extension staff should be provided

- Training of the present extension staff should be addressed

- Agencies that can be involved and participate in providing extension services should be identified

- The farmers in terms of their capabilities (gender, resources, markets, culture), should be fully understood and technologies only relevant to each farmer's capability should be ensured.

- Network and enhance.

\section{REFERENCES}

Allahyari, M.S., 2009. Agricultural sustainability: Implications for extension systems. African J. Agric. Res., 4: 781-786.
Azril, H., U. Jegak, M. Asiah, A.N. Azman and A.S. Bahaman et al., 2010. Can quality of work life affect work performance among goverment agriculture extension officers? A case from Malaysia. J. Soc. Sci., 1: 64-73. DOI: 10.3844/jssp.2010.64.73

Cho, K.M. and H., Boland, 2004. Education and extension for multi-functional agriculture: Extension concepts for sustainable agricultural development in Myanmar. Proceedings of 20th Annual Conference of AIAEE, May 23-29, Dublin, Ireland, pp: 531-537.

Demiryurek, K., 1999. The Analysis of Information Systems for Organic and Conventional Hazelnut Producers in three Villages of the Black Sea Region, Turkey. 1st Edn., University of Reading, pp: 744.

Hindi, M.A.S., 2009. Attitudes of vegetable farmers towards risk in the Jordan Valley. Emirates J. Food Agric., 2: 51-63.

Hosseini, S.J.F., M. Niknami and G.H. Nejad, 2009. Policies affect the application of information and communication technologies by agricultural extension service. Am. J. Applied Sci., 8: 14781483. DOI: 10.3844/ajassp.2009.1478.1483

Hu, R., Z. Yang, P. Kelly and J. Huang, 2009. Agricultural extension system reform and agent time allocation in China. China Econ. Rev., 20: 303-315. DOI: $10.1016 /$ j.chieco.2008.10.009

IBRDWB, 1994. Agricultural Extension: Lessons from Completed Projects. 1st Edn., World Bank, Washington, pp: 74.

Karbasioun, M., M. Mulder and H. Biemans, 2007. Towards a job competency profile for agricultural extension instructors-a survey of views of experts. Hum. Resou. Dev. Int., 10: 137-151.

Kumar, P.G. and R. Ratnakar, 2011. A scale to measure farmers' attitude towards ICT-based extension services. Indian Res. J. Extension Educ., 11: 109-112.

Mastura, J., T. Ramayah and Z. Zainurin, 2006. Work statisfaction and work performance: how project managers in malaysia perceive it? Proceedings of the 2nd Biennial Conference of the Academy of World Business Marketing and Management Development, Jul. 10-13, Paris, France.

MoA, 2009. The agricultural statistics report the Jordanian ministry of agriculture. Ministry of Agriculture.

Rivera, W.M., 1987. Agricultural Extension Worldwide: Issues Practices and Emerging Priorities. 1st Edn., Croom Helm, London, ISBN-10: 0709942389, pp: 294.

Seevers, B., 1997. Education through Cooperative Extension. 1st Edn., Delmar Publishers, Albany, ISBN-10: 0827371721, pp: 288. 
Swanson, B.E., 2009. Changing Extension paradigms within a rapidly changing global economy. Proceeding of the 19th European Seminar on Extension Education, (ESEE' 09), pp: 113-117.

Tella, A., C.O. Ayeni and S.O. Popoola, 2007. Work motivation, job satisfaction and organisational commitment of library personnel in academic and research libraries in Oyo state, Nigeria. J. Library Philosophy Pract., 9: 1-16.

Umali-Deininger, D. and L.A. Schwartz, 1994. Public and Private Agricultural Extension: Beyond Traditional Frontiers. 1st Edn., World Bank discussion papers, Washington, ISBN-10: 0821328034, pp: 82.
USAID, 2005. Assessment of agricultural extension services in Jordan Vally and Amman-Zarqa Basin Highlands in Jordan. Office of Water Resources and Environment American Embassy, Amman, Jordan.

Vagias, W.M., 2006. Likert-type scale response anchors. Clemson University. 